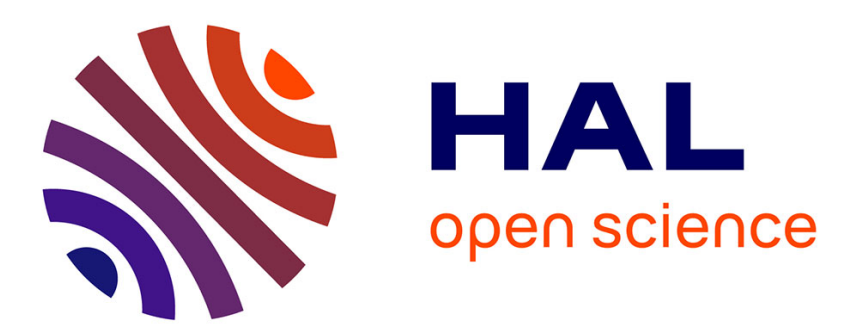

\title{
The Taylor principle and global determinacy in a non Ricardian world
}

\author{
Jean-Pascal Bénassy, Michel Guillard
}

\section{To cite this version:}

Jean-Pascal Bénassy, Michel Guillard. The Taylor principle and global determinacy in a non Ricardian world. 2005. halshs-00590558

\section{HAL Id: halshs-00590558 \\ https://shs.hal.science/halshs-00590558}

Preprint submitted on 3 May 2011

HAL is a multi-disciplinary open access archive for the deposit and dissemination of scientific research documents, whether they are published or not. The documents may come from teaching and research institutions in France or abroad, or from public or private research centers.
L'archive ouverte pluridisciplinaire HAL, est destinée au dépôt et à la diffusion de documents scientifiques de niveau recherche, publiés ou non, émanant des établissements d'enseignement et de recherche français ou étrangers, des laboratoires publics ou privés. 
WORKING PAPER № 2005 - 50

The Taylor principle and global determinacy

in a non Ricardian world

Jean-Pascal Bénassy

Michel Guillard

JEL Codes : E52, E63

Keywords : Taylor principle, Taylor rules, global determinacy, price determinacy, non Ricardian economies, non Ricardian equilibria 


\title{
The Taylor Principle and Global Determinacy in a non Ricardian World
}

\author{
Jean-Pascal Bénassy*† and Michel Guillard ${ }^{\ddagger \S}$ \\ January 2005 \\ Revised December 2005
}

\begin{abstract}
The Taylor principle is quite usually considered as a central condition for price determinacy. Recently, however, this has been questioned on several grounds, notably because $(i)$ this condition is a condition for local determinacy, not global determinacy (ii) it has been derived in "Ricardian" economies, and it appears that going to a nonRicardian framework makes a very big difference for the determinacy conditions. In this paper we scrutinize the two issues together, and we find that for non-Ricardian equilibria the Taylor principle is replaced by another "financial dominance" criterion.
\end{abstract}

JEL Codes: E52, E63

Keywords: Taylor Principle, Taylor Rules, Global Determinacy, Price Determinacy, Non-Ricardian Economies, Non-Ricardian equilibria.

\footnotetext{
${ }^{*} \mathrm{PSE}$ and CEPREMAP

${ }^{\dagger}$ Address: CEPREMAP-ENS, 48 Boulevard Jourdan, Bâtiment E, 75014, Paris, France. Telephone: 33-1-43136338. Fax: 33-1-43136232. E-mail: benassy@pse.ens.fr

${ }^{\ddagger}$ EPEE and Université d'Evry

§Address: EPEE, Université d'Evry, 4 Boulevard François Mitterrand, 91025 Evry Cedex, France. Telephone: 33-1-69477048. Fax: 33-1-69477050. E-mail: guillard@univ-
} evry.fr 


\section{Introduction}

Ever since Taylor's (1993) seminal article on interest rate rules, many authors have tried to assess the conditions under which interest rate rules lead to price determinacy, as this is a clear condition for the "stability" of the economic system. In the late years a consensus seems to have emerged that the "Taylor principle" is an important condition for determinacy. In its simplest and most well-known version this principle says that the nominal interest rate should respond more than hundred percent to the rate of inflation. Under the Taylor principle the real interest rate responds positively to inflation, and this is supposed to have a stabilizing influence on the economy (Taylor, 1998).

Now this consensus has been questioned recently on several grounds: (a) The Taylor principle is a condition for local determinacy, not global determinacy, and it may well be that an equilibrium where it is satisfied is locally, but not globally determinate. As a result other constraints on policy may be necessary to regain global determinacy (Benhabib, Schmitt-Grohe and Uribe, 2001a,b, 2002, Woodford, 1999, 2003). (b) The determinacy results on the Taylor principle have been derived in "Ricardian" economies, i.e. in economies with a single infinitely lived dynasty of agents where Ricardian equivalence (Barro 1974) holds. But it appears that going to non-Ricardian economies where new agents appear over time makes a substantial difference for the determinacy conditions (Bénassy, 2000, 2005). Notably Bénassy (2005) shows that in a non-Ricardian economy the relevant local determinacy condition is not the Taylor principle, but a "financial dominance" (FD) condition $^{1}$, which extends earlier conditions derived by Wallace (1980) for an overlapping generations model à la Samuelson (1958). Now in this paper we shall scrutinize the two issues together, and study global determinacy in non-Ricardian economies. We shall find out that a global version of the financial dominance criterion is central in ensuring global determinacy.

\section{The model}

We shall use a model due to Weil $(1987,1991)$, which has the great advantage of having the Ricardian model as a particular case. Each household lives forever, but new "generations" are born every period, as in the overlapping generations model. Denote as $N_{t}$ the number of households alive at time $t$. So $N_{t}-N_{t-1} \geq 0$ households are born in period $t$. We will actually mainly work below with a constant rate of growth of the population $n \geq 0$, so that $N_{t}=(1+n)^{t} N_{0}$. The Ricardian model corresponds to the special case $n=0$.

\footnotetext{
${ }^{1} \mathrm{~A}$ precise definition is given in definition 1 below.
} 


\subsection{Households}

Consider a household born in period $j$. We denote by $c_{j t}, y_{j t}$ and $m_{j t}$ his consumption, endowment and money holdings at time $t \geq j$. This household maximizes the following utility function:

$$
U_{j t}=\sum_{s=t}^{\infty} \beta^{s-t} \log c_{j s}
$$

and is submitted in period $t$ to a "cash in advance" constraint:

$$
P_{t} c_{j t} \leq m_{j t}
$$

Household $j$ begins period $t$ with a financial wealth $\omega_{j t}$. First the bond market opens, and the household lends an amount $b_{j t}$ at the nominal interest rate $i_{t}$. The rest is kept under the form of money $m_{j t}$, so that:

$$
\omega_{j t}=m_{j t}+b_{j t}
$$

Then the goods market opens, and the household sells his endowment $y_{j t}$, pays taxes $\tau_{j t}$ in real terms and consumes $c_{j t}$, subject to the cash constraint (2). Consequently, the budget constraint for the household is:

$$
\omega_{j t+1}=\left(1+i_{t}\right) \omega_{j t}-i_{t} m_{j t}+P_{t} y_{j t}-P_{t} \tau_{j t}-P_{t} c_{j t}
$$

\subsection{Aggregation, endowments and taxes}

Aggregate quantities are obtained by summing the various individual variables. There are $N_{j}-N_{j-1}$ agents in generation $j$, so for example aggregate taxes $T_{t}$ are given by:

$$
T_{t}=\sum_{j \leq t}\left(N_{j}-N_{j-1}\right) \tau_{j t}
$$

The other aggregate quantities, $Y_{t}, C_{t}, \Omega_{t}, M_{t}$ and $B_{t}$, are deduced through similar formulas from the individual variables, $y_{j t}, c_{j t}, \omega_{j t}, m_{j t}$ and $b_{j t}$.

We now have to describe the distribution of endowments and taxes among households. We assume that all households have the same income and taxes:

$$
y_{j t}=y_{t}=\frac{Y_{t}}{N_{t}} \quad \tau_{j t}=\tau_{t}=\frac{T_{t}}{N_{t}}
$$

For the rest of the paper, we shall assume that output per head grows at a constant gross rate $\gamma$, so that:

$$
\frac{y_{t+1}}{y_{t}}=\gamma \quad \frac{Y_{t+1}}{Y_{t}}=(1+n) \gamma
$$




\section{Government and policy}

The households' aggregate financial wealth $\Omega_{t}$ has as a counterpart an identical amount $\Omega_{t}$ of financial liabilities of the government. These are decomposed into money and bonds:

$$
\Omega_{t}=M_{t}+B_{t}
$$

The evolution of $\Omega_{t}$ is described by the government's budget constraint:

$$
\Omega_{t+1}=\left(1+i_{t}\right) \Omega_{t}-i_{t} M_{t}-P_{t} T_{t}
$$

To simplify the exposition we assume that government spending is zero.

\subsection{Monetary policy}

Monetary policy takes the form of "Taylor rules" linking the value of the nominal interest rate to inflation and respecting the zero lower bound on nominal interest rate:

$$
1+i_{t}=\Phi\left(\Pi_{t}\right) \geq 1, \quad \forall \Pi_{t}
$$

with:

$$
\Pi_{t}=\frac{P_{t}}{P_{t-1}}
$$

We shall assume:

$$
\Phi^{\prime}\left(\Pi_{t}\right) \geq 0
$$

An important parameter is the elasticity of the function $\Phi$ :

$$
\phi\left(\Pi_{t}\right)=\frac{\Pi_{t} \Phi^{\prime}\left(\Pi_{t}\right)}{\Phi\left(\Pi_{t}\right)}
$$

The famous "Taylor principle" (Taylor, 1993, 1998) says that this elasticity should be greater than 1 . Note that, because of the constraint that the nominal interest rate must be greater than zero, the "Taylor principle" cannot be verified for all values of $\Pi_{t}$.

A well-known example of an interest rate rule is interest rate pegging:

$$
\Phi\left(\Pi_{t}\right)=1+\hat{\imath}_{t} \quad \forall \Pi_{t} \geq 0
$$

where the sequence $\hat{\imath}_{t}$ is exogenous. This rule clearly does not satify the Taylor principle. It is of particular interest because, in the usual Ricardian framework, it leads to nominal indeterminacy (Sargent and Wallace, 1975). 


\subsection{Fiscal policy}

Since the object of our study is monetary policy, we shall take the simplest possible fiscal policies. If the budget was balanced, taxes would be equal to interest payments on bonds $i_{t} B_{t}$, so that one would have:

$$
P_{t} T_{t}=i_{t} B_{t}
$$

Because the rate of expansion of government liabilities will play a substantial role below, we shall actually assume a more general class of policies, of the form:

$$
P_{t} T_{t}=i_{t} B_{t}+(1-\Lambda) \Omega_{t} ; \quad \Lambda>0
$$

As compared to the balanced budget policy (15), the term $(1-\Lambda) \Omega_{t}$ has been added. It says that the government may want to withdraw a fraction $1-\Lambda$ of its outstanding financial liabilities. If $\Lambda$ is greater than 1 , this actually corresponds to an expansion of government liabilities.

\section{Dynamics}

Putting together equations (8), (9) and (16), we first find the equation of evolution of $\Omega_{t}$ :

$$
\Omega_{t+1}=\Lambda \Omega_{t}
$$

Now it is shown in appendix 1 that the dynamics of nominal income is given by:

$$
P_{t+1} Y_{t+1}=\beta(1+n)\left(1+i_{t}\right) P_{t} Y_{t}-(1-\beta) n \Omega_{t+1}
$$

Equations (17) and (18) are the two basic dynamic equations. Now let us define the real gross rate of interest $R_{t}$ as:

$$
R_{t}=\left(1+i_{t}\right) \frac{P_{t}}{P_{t+1}}
$$

Equation (18) can be transformed into an equation in $R_{t}$ :

$$
R_{t}=R^{0}+\frac{(1-\beta) \gamma n}{\beta} \frac{\Omega_{t+1}}{P_{t+1} Y_{t+1}}
$$

where :

$$
R^{0}=\frac{\gamma}{\beta}
$$

$R^{0}$ is the equilibrium value of the real rate of interest in the Ricardian economy. It is also called the "autarkic" real interest rate, because it is the real interest rate that would prevail if members of each generation only traded between themselves, hence the name "autarkic".

We may also note that, using (10) and (11), (19) can be rewritten as:

$$
\Pi_{t+1}=\frac{\Phi\left(\Pi_{t}\right)}{R_{t}}
$$




\section{The Ricardian world}

We shall begin our investigation with the traditional Ricardian model with a single dynasty of infinitely lived agents. For that it is enough to take $n=0$. Equation (20) then simplifies as:

$$
R_{t}=R^{0}
$$

In view of $(23),(22)$ is rewritten as:

$$
\Pi_{t+1}=\frac{\Phi\left(\Pi_{t}\right)}{R^{0}}
$$

\subsection{Steady states}

The potential steady state values of $\Pi_{t}$, denoted as $\Pi$, are solutions of the equation:

$$
\Phi(\Pi)=\Pi R^{0}
$$

We shall denote as $\Pi^{k}, k=1, \ldots . . K$, the solutions of this equation, ranked in ascending order. Depending on the properties of the function $\Phi$, and the value of $R^{0}$, equation (25) can have potentially any number of solutions, including zero ${ }^{2}$.

\subsection{Existence and transversality conditions}

Steady state equilibria exist if and only if the households' transversality conditions are verified. Without population growth, the representative household transversality condition is given by:

$$
\lim _{T \rightarrow \infty} Q_{T}\left(\frac{\Omega_{T}}{N_{0}}\right)=0
$$

where:

$$
Q_{T}=\frac{1}{\left(1+i_{0}\right) \ldots\left(1+i_{T-1}\right)}
$$

At a stationary equilibrium, using $1+i=\Pi R^{0}$ and (17), (26) is equivalent to:

$$
\lim _{T \rightarrow \infty}\left(\frac{\Lambda}{\Pi R^{0}}\right)^{T}\left(\frac{\Omega_{0}}{N_{0}}\right)=0
$$

For $\Omega_{0} \neq 0$, this equation is verified if and only if $\Lambda / \Pi R^{0}<1$, that is:

$$
\frac{\Lambda}{R^{0}}<\Pi
$$

\footnotetext{
${ }^{2}$ We may note that the condition $\phi^{\prime}\left(\Pi_{t}\right) \geq 0$ is actually sufficient to have no more than 2 solutions.
} 


\subsection{Local determinacy}

From (24), the condition for local determinacy at a potential equilibrium $\Pi^{k}$ is simply given by:

$$
\left.\frac{\partial \Pi_{t+1}}{\partial \Pi_{t}}\right|_{\Pi^{k}}=\frac{\Phi^{\prime}\left(\Pi^{k}\right)}{R^{0}}>1
$$

or, using (25):

$$
\phi\left(\Pi^{k}\right)=\frac{\Pi^{k} \Phi^{\prime}\left(\Pi^{k}\right)}{\Phi\left(\Pi^{k}\right)}>1
$$

So, if the elasticity of the function $\Phi\left(\Pi_{t}\right)$ is greater than 1 , the inflation rate and the price level are locally determinate. This is the Taylor principle.

\subsection{Global determinacy}

Let us begin with the simple case where equation (25) has two solutions, i.e. $K=2$. The corresponding dynamics is depicted in figure 1 , which represents equation (24).

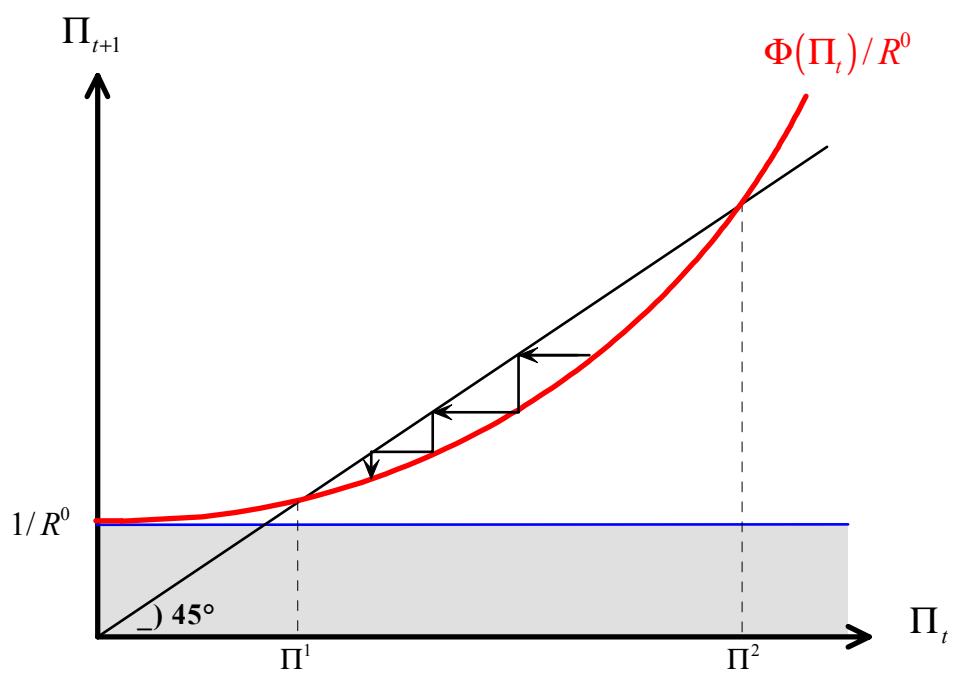

Figure 1

As we can see in figure 1 , if there is an equilibrium $\Pi^{2}$ where $\phi\left(\Pi^{2}\right)>1$, because of the zero lower bound on the nominal interest rate, there must be another equilibrium $\Pi^{1}$ where the Taylor principle is not satisfied, i.e. where $\phi\left(\Pi^{1}\right)<1$, and which is locally indeterminate. This indeterminate equilibrium is sometimes called "liquidity trap". This "liquidity trap" equilibrium exists if the transversality condition (29) holds, i.e. if:

$$
\frac{\Lambda}{R^{0}}<\Pi^{1}
$$


All dynamic paths initiating between the two equilibria converge towards the liquidity trap equilibrium. Conversely, the condition:

$$
\Pi^{1}<\frac{\Lambda}{R^{0}}<\Pi^{2}
$$

eliminates the potential equilibrium $\Pi^{1}$ and is sufficient to ensure global determinacy. More generally if there are $K$ potential equilibria we have the following result (Woodford, 1999, 2003, Benhabib, Schmitt-Grohe and Uribe, 2002, Alstadheim and Henderson, 2004):

Proposition 1 If there are potential equilibria $\Pi^{1}, \ldots, \Pi^{k}, \ldots, \Pi^{K}$, then $\Pi^{K}$ is determinate if:

$$
\begin{gathered}
\phi\left(\Pi^{K}\right)>1 \\
\Pi^{K-1}<\frac{\Lambda}{R^{0}}<\Pi^{K}
\end{gathered}
$$

We see that the Taylor principle (34) is supplemented with a condition ensuring that only the equilibrium corresponding to the highest inflation satisfies the transversality conditions.

\section{Non Ricardian economies: steady states and existence}

Let us now return to non Ricardian economies where $n>0$, and recall the dynamic equations:

$$
\begin{gathered}
\Omega_{t+1}=\Lambda \Omega_{t} \\
P_{t+1} Y_{t+1}=\beta(1+n)\left(1+i_{t}\right) P_{t} Y_{t}-(1-\beta) n \Omega_{t+1}
\end{gathered}
$$

It will actually be convenient to use as working variables inflation $\Pi_{t}$ and the predetermined variable $X_{t}$ defined as:

$$
X_{t}=\frac{\Omega_{t}}{P_{t-1} Y_{t-1}}
$$

Then, using again $R^{0}=\gamma / \beta$, the dynamic system can be written:

$$
\begin{aligned}
X_{t+1} & =\frac{\Lambda}{\gamma(1+n)} \frac{X_{t}}{\Pi_{t}} \\
\Pi_{t+1} & =\frac{\Phi\left(\Pi_{t}\right)}{R^{0}}-\delta X_{t+1}
\end{aligned}
$$

with:

$$
\delta=\frac{n}{1+n} \frac{1-\beta}{\gamma}>0
$$




\subsection{Steady states}

From (39) and (40) potential steady states $\Pi$ and $X$ are solutions of the two equations:

$$
\begin{aligned}
& X=\frac{\Lambda}{\gamma(1+n)} \frac{X}{\Pi} \\
& \Pi=\frac{\Phi(\Pi)}{R^{0}}-\delta X
\end{aligned}
$$

We see that there are two types of equilibria:

$$
\Pi^{k}=\frac{\Phi\left(\Pi^{k}\right)}{R^{0}}, \quad X^{k}=0 \quad(k=1,2, \ldots K) \quad \text { Type } \mathcal{R}
$$

and:

$$
\Pi^{*}=\frac{\Lambda}{\gamma(1+n)}, \quad X^{*}=\frac{1}{\delta R^{0}}\left[\Phi\left(\Pi^{*}\right)-\Pi^{*} R^{0}\right] \quad \text { Type } \mathcal{N} \mathcal{R}
$$

Steady states of type $\mathcal{R}$ (like "Ricardian") are similar to the steady states in Ricardian economies, since in both cases the potential equilibrium rates of inflation are given by equations (25) or (44). By (44) the real gross rate of interest is equal to $R^{0}$, whatever the value of the inflation rate. There is a difference, though: in a non Ricardian economy the corresponding stationary value of $X$ is equal to zero.

The (unique) steady state of type $\mathcal{N} \mathcal{R}$ is more specific to the non-Ricardian environment we investigate here, and these equilibria will be the principal object of our study. The inflation rate $\Pi^{*}$ is not given anymore by the properties of the Taylor rule (equations 25 or 44), but is equal to the rate of growth $\Lambda$ of governmental financial liabilities divided by the rate of growth of output, a traditional formula. The real gross rate of interest, noted $R^{*}$, is not equal to $R^{0}$, but is deduced from $\Pi^{*}$ by:

$$
R^{*}=\frac{\Phi\left(\Pi^{*}\right)}{\Pi^{*}}
$$

\subsection{Existence and transversality conditions}

Potential equilibria, as defined by equations (44) or (45), will be actual equilibria if and only if the households' transversality conditions are verified. Because of population growth, we must use an adapted version of a representative household's transversality condition:

$$
\lim _{T \rightarrow \infty} Q_{T}\left(\frac{\Omega_{T}}{N_{T}}\right)=0
$$


with again $Q_{T}=\left[\left(1+i_{0}\right) \ldots\left(1+i_{T-1}\right)\right]^{-1}$. At stationary equilibria, using $1+i=\Pi R$ and the dynamic equation (36), (47) is equivalent to:

$$
\lim _{T \rightarrow \infty}\left[\frac{\Lambda}{(1+n) \Pi R}\right]^{T}\left(\frac{\Omega_{0}}{N_{0}}\right)=0
$$

For $\Omega_{0} \neq 0$, this equation is verified if and only if $\Lambda /(1+n) \Pi R<1$, or:

$$
\frac{\Lambda}{1+n}<\Pi R
$$

We must consider two cases:

1. For steady states of type $\mathcal{R}$, as we have already noted, the stationary real rate of interest $R$ is equal to $R^{0}$, so (49) simplifies as:

$$
\frac{\Lambda}{(1+n) R_{0}}<\Pi^{k}
$$

2. For the steady state of type $\mathcal{N} \mathcal{R}$, using the definition of $\Pi^{*}$ given by (45), condition (49) can be rewritten:

$$
\gamma<R^{*}
$$

But in view of the definition of $X^{*}$ given by (45) and inspecting again equation (39), we note that if $X_{0}>0, X^{*}$ must necessarily be positive, implying:

$$
R^{0}<R^{*}=\frac{\Phi\left(\Pi^{*}\right)}{\Pi^{*}}
$$

Then, because $\gamma<\gamma / \beta=R^{0}$, conditions (49) and (51) hold and the transversality condition is always satisfied at the non-Ricardian equilibrium.

\section{$7 \quad$ Financial dominance and local determinacy}

We already mentioned a few times that a criterion different from the Taylor principle, the "financial dominance" criterion, will play a very important role in our local and global determinacy conditions. It is now time to give a formal definition ${ }^{3}$.

Definition 1: We shall say that the "financial dominance" (FD) criterion is satisfied for the value of inflation $\Pi$ if:

$$
\frac{\Phi(\Pi)}{\Pi}>R^{0}
$$

\footnotetext{
${ }^{3}$ This criterion appears initially in Wallace (1980) for an OLG economy where money is the single store of value. It is extended in Bénassy (2005) for economies with both money and bonds.
} 
or, in words, the steady state real interest rate $\Phi(\Pi) / \Pi$ generated by the monetary rule is above the autarkic rate $R^{0}$.

In order to characterize financial dominance with a simple parameter, let us define:

$$
\mu(\Pi)=\frac{1}{R^{0}} \frac{\Phi(\Pi)}{\Pi}
$$

The financial dominance (FD) criterion holds if:

$$
\mu(\Pi)>1
$$

\subsection{Local determinacy}

We shall now study first the local determinacy of our potential equilibria. Linearizing the dynamic system (40) and (39), and using (42) and (43), we obtain the following linearized system:

$$
\left[\begin{array}{c}
\Pi_{t+1}-\Pi \\
X_{t+1}-X
\end{array}\right]=\left[\begin{array}{cc}
\mu \phi+(\mu-1) & -\delta \Pi^{*} / \Pi \\
-(\mu-1) / \delta & \Pi^{*} / \Pi
\end{array}\right]\left[\begin{array}{c}
\Pi_{t}-\Pi \\
X_{t}-X
\end{array}\right]
$$

with:

$$
\phi=\phi(\Pi) \quad \mu=\mu(\Pi) \quad \Pi^{*}=\frac{\Lambda}{\gamma(1+n)}
$$

The characteristic polynomial $\Psi$ corresponding to this linearized dynamic system is given by:

$$
\Psi(\lambda)=(\lambda-\mu \phi)\left(\lambda-\frac{\Pi^{*}}{\Pi}\right)+(1-\mu) \frac{\Pi^{*}}{\Pi} \lambda
$$

We shall now examine in turn Ricardian and non Ricardian equilibria.

\section{2 $\quad$ Steady states of type $\mathcal{R}$}

For steady states of type $\mathcal{R}$ given by equation (44) we have $R=R^{0}$ and $\mu=1$, so that equation (58) becomes:

$$
\Psi_{\mathcal{R}}(\lambda)=\left(\lambda-\phi^{k}\right)\left(\lambda-\frac{\Pi^{*}}{\Pi^{k}}\right)
$$

This characteristic polynomial has the two roots:

$$
\lambda_{1}=\phi^{k} ; \quad \lambda_{2}=\frac{\Pi^{*}}{\Pi^{k}} .
$$

There is local determinacy if one of these roots is of modulus greater than 1 , the other smaller than 1 , that is if:

$$
\phi^{k}<1 \quad \text { and } \quad \Pi^{k}<\Pi^{*}
$$


or:

$$
\phi^{k}>1 \quad \text { and } \quad \Pi^{k}>\Pi^{*}
$$

We may note here that the Taylor principle does play a role for local determinacy of Ricardian equilibria. We shall now see that this ceases to be the case for non-Ricardian equilibria.

\subsection{Steady states of type $\mathcal{N} \mathcal{R}$}

Now for the steady state of type $\mathcal{N} \mathcal{R}$ we have $\Pi=\Pi^{*}$, so the associated characteristic polynomial is:

$$
\Psi_{\mathcal{N R}}(\lambda)=(\lambda-\mu \phi)(\lambda-1)+(1-\mu) \lambda
$$

We can compute:

$$
\begin{gathered}
\Psi_{\mathcal{N R}}(0)=\phi \mu>0 \\
\Psi_{\mathcal{N R}}(1)=1-\mu
\end{gathered}
$$

We see that the condition for local determinacy is:

$$
\mu>1
$$

So for the steady state of type $\mathcal{N} \mathcal{R}$ the financial dominance criterion becomes the relevant one, at least for local determinacy. We shall now see that this is also the case for global determinacy.

\section{Non Ricardian economies: global determi- nacy}

We shall now study under which conditions global determinacy holds in a non-Ricardian environment. We shall see that the Taylor principle will be almost completely replaced by the "financial dominance" criterion.

\subsection{A graphical representation}

Since we shall make extensive use of graphical representations below, we begin with it. The curve $X_{t+1}=X_{t}$ has two "branches" whose equations are (cf equation 39):

$$
X_{t}=0 \quad \text { and } \quad \Pi_{t}=\Pi^{*}
$$

while the equation of the curve $\Pi_{t+1}=\Pi_{t}$ can be written (cf equation 40):

$$
X_{t}=\Gamma\left(\Pi_{t}\right)
$$

with: 


$$
\Gamma\left(\Pi_{t}\right)=\frac{\Pi_{t}}{\delta \Pi^{*}}\left[\frac{\Phi\left(\Pi_{t}\right)}{R^{0}}-\Pi_{t}\right]
$$

We may further note that:

$$
X_{t+1}>X_{t} \quad \text { if : } \quad \Pi_{t}<\Pi^{*} \text { and } X_{t}>0
$$

and:

$$
\Pi_{t+1}>\Pi_{t} \quad \text { if: } \quad X_{t}<\Gamma\left(\Pi_{t}\right)
$$

It will be useful in what follows to link satisfaction of the Taylor principle to the slope of the function $\Gamma$ (equation 69 ). So we have:

Lemma 1: Consider a potential equilibrium of type $\mathcal{R}$, denoted as $\Pi^{k}$, and corresponding to a point where the curve $X_{t}=\Gamma\left(\Pi_{t}\right)$ cuts the horizontal axis. At such a point:

- If the slope of $\Gamma$ is negative, then $\phi\left(\Pi^{k}\right)<1$.

- If the slope of $\Gamma$ is positive, then $\phi\left(\Pi^{k}\right)>1$.

Proof: Compute the derivative of $\Gamma$ at the point $\Pi^{k}$. Using the fact that $\Phi\left(\Pi_{t}\right)=\Pi_{t} R^{0}$ we find:

$$
\Gamma^{\prime}\left(\Pi^{k}\right)=\frac{\Pi^{k}}{\delta \Pi^{*}}\left[\phi\left(\Pi^{k}\right)-1\right]
$$

which trivially implies the result.

\subsection{Strong financial dominance}

We shall now see how the financial dominance criterion can ensure global determinacy through the following proposition:

Proposition 2 If the financial dominance criterion holds for all values of the inflation rate, i.e. if:

$$
\frac{\Phi\left(\Pi_{t}\right)}{\Pi_{t}}>R^{0} \quad \forall \Pi_{t}
$$

Then there is a single globally determinate equilibrium of type $\mathcal{N} \mathcal{R}$.

Proof. Figure 2 depicts the two curves $X_{t+1}=X_{t}$ and $\Pi_{t+1}=\Pi_{t}$, as well as the dynamics of the economy given by (70) and (71), under condition (73). We first see that there cannot be an equilibrium of type $\mathcal{R}$ since these equilibria are all characterized by $\Phi(\Pi)=\Pi R^{0}$, which is inconsistent with 
(73). So there remains only the unique equilibrium of type $\mathcal{N} \mathcal{R}$. Now since $\mu\left(\Pi^{*}\right)>1$, we know from the results of section 7.3 that this equilibrium is characterized by saddle-point dynamics and is locally determinate. It is further easy to see from the dynamics depicted in figure 2 that this equilibrium is globally determinate.

It is noteworthy that the preceding result does not depend on the elasticity of the function $\Phi$ as long as condition (73) applies. In other words, the Taylor principle is irrelevant for local and global determinacy when condition (73) applies.

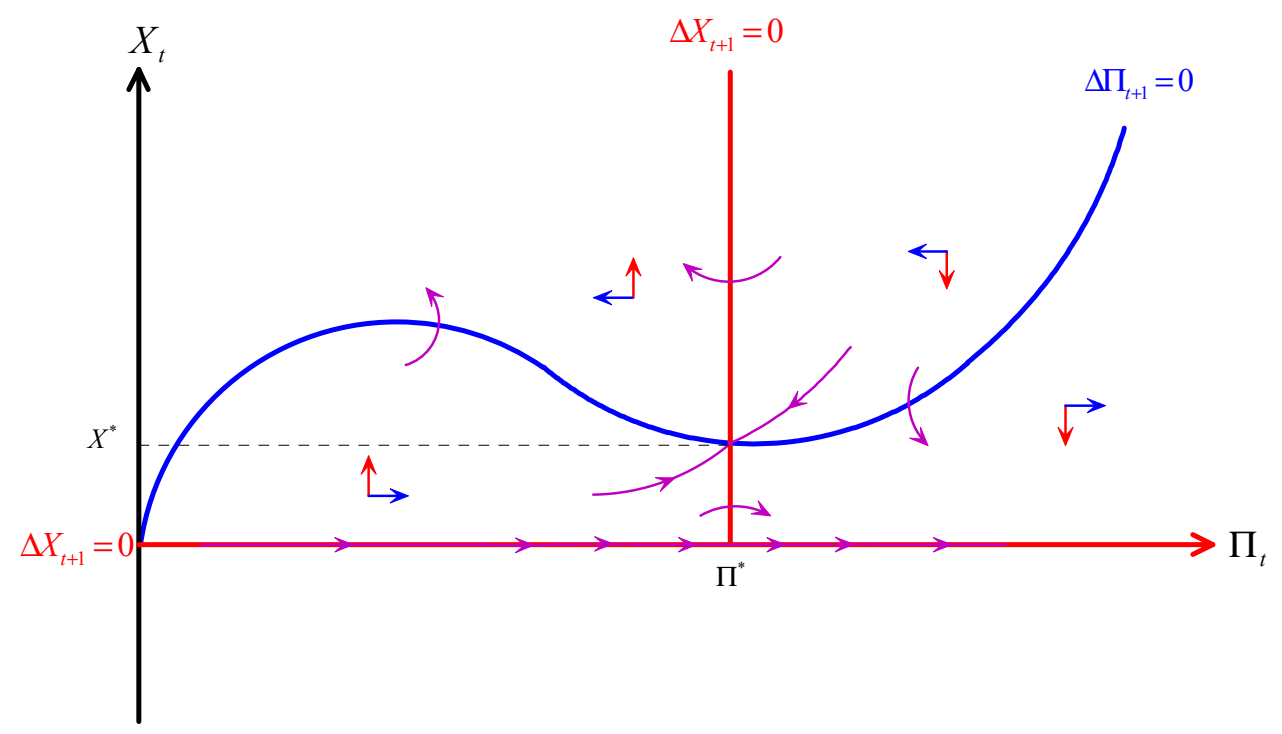

Figure 2

\subsection{Partial financial dominance}

We shall now consider cases where the financial dominance criterion is not satisfied for all values of the inflation rate, and see that nevertheless this criterion plays a central role in achieving global determinacy.

Proposition 3 Consider a potential equilibrium of type $\mathcal{N} \mathcal{R}$, notably characterized by an inflation rate $\Pi^{*}$ such that $\Phi\left(\Pi^{*}\right) / \Pi^{*}>R^{0}$. Then this equilibrium is globally determinate if and only if:

$$
\frac{\Phi\left(\Pi_{t}\right)}{\Pi_{t}}>R^{0} \quad \forall \Pi_{t} \geq \Pi^{*}
$$

Proof. (a) We shall begin by showing that condition (74) is necessary. If (74) is not satisfied, then there must be a value $\Pi^{1}>\Pi^{*}$ such that $\Phi\left(\Pi^{1}\right)=R^{0} \Pi^{1}$, 
i.e. such that $\Pi^{1}$ is a potential equilibrium of type $\mathcal{R}$. This is depicted in figure 3 . We see in figure 3 that, in addition to the non Ricardian equilibrium (type $\mathcal{N} \mathcal{R}$ ) corresponding to $\Pi^{*}$, there is at least one potential equilibrium of type $\mathcal{R}$, corresponding to the inflation rate $\Pi^{1}$. The equilibrium $\Pi^{*}$ is locally determinate. The equilibrium $\Pi^{1}$, however, is indeterminate. Indeed $\phi\left(\Pi^{1}\right)<1$ by lemma 1 . The results of section 7.2 then show that the two roots at equilibrium $\Pi^{1}$ are $\Pi^{*} / \Pi^{1}$ and $\phi\left(\Pi^{1}\right)$, both of modulus smaller than 1. The dynamic system is thus globally indeterminate, and condition (74) is indeed necessary.

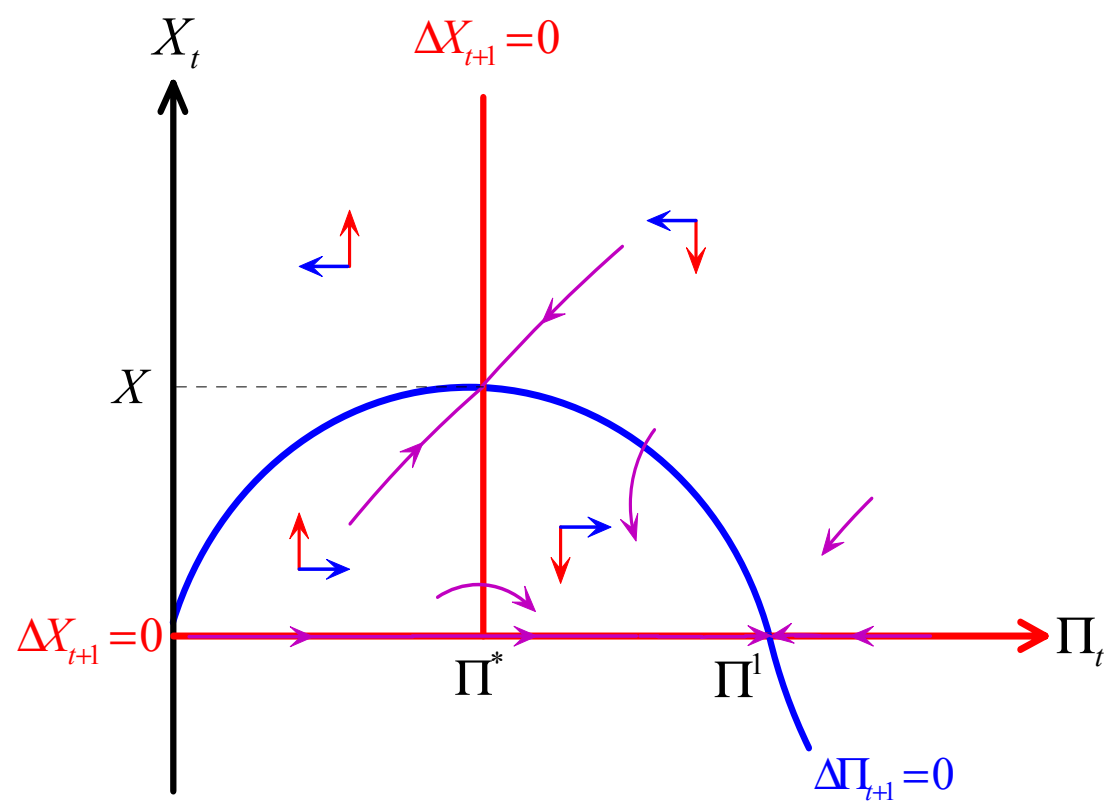

Figure 3

(b) We shall now show that condition (74) is sufficient for global determinacy. We have actually already dealt with the case where the curve $X_{t}=\Gamma\left(\Pi_{t}\right)$ is entirely above the horizontal axis (proposition 2). So we shall now study cases where it intersects the horizontal axis. When (74) applies, there does not exist a value $\Pi>\Pi^{*}$ such that $\Phi(\Pi)=\Pi R^{0}$. But there may exist an even number of values $\Pi<\Pi^{*}$ which satisfy this equation. Figure 4 represents the case where there are two such values, $\Pi^{1}$ and $\Pi^{2}$. For the equilibrium of type $\mathcal{N} \mathcal{R}$, corresponding to $\Pi^{*}$, to be globally determinate, we need these two other potential equilibria not to be reachable.

So let us first consider $\Pi^{1}$. From section 7.2 we know that the two roots are $\phi\left(\Pi^{1}\right)<1$ (from lemma 1) and $\Pi^{*} / \Pi^{1}>1$. We thus have saddle path dynamics. The problem, however, is that the "converging branch" of this saddle path dynamics is contained in the horizontal axis, so that if $X_{0}>0$ this equilibrium can never be reached.

Let us now consider $\Pi^{2}$. The two roots are $\phi\left(\Pi^{2}\right)>1$ (from lemma 1) and 
$\Pi^{*} / \Pi^{2}>1$. In that case since the two roots are of modulus greater than 1 , this potential equilibrium will never be reached either.

So to summarize, we have one equilibrium of type $\mathcal{N} \mathcal{R}$ which displays saddle path dynamics, and two potential equilibria of type $\mathcal{R}$ which can never be reached. The equilibrium of type $\mathcal{N} \mathcal{R}$ is globally determinate, as figure 4 clearly shows.

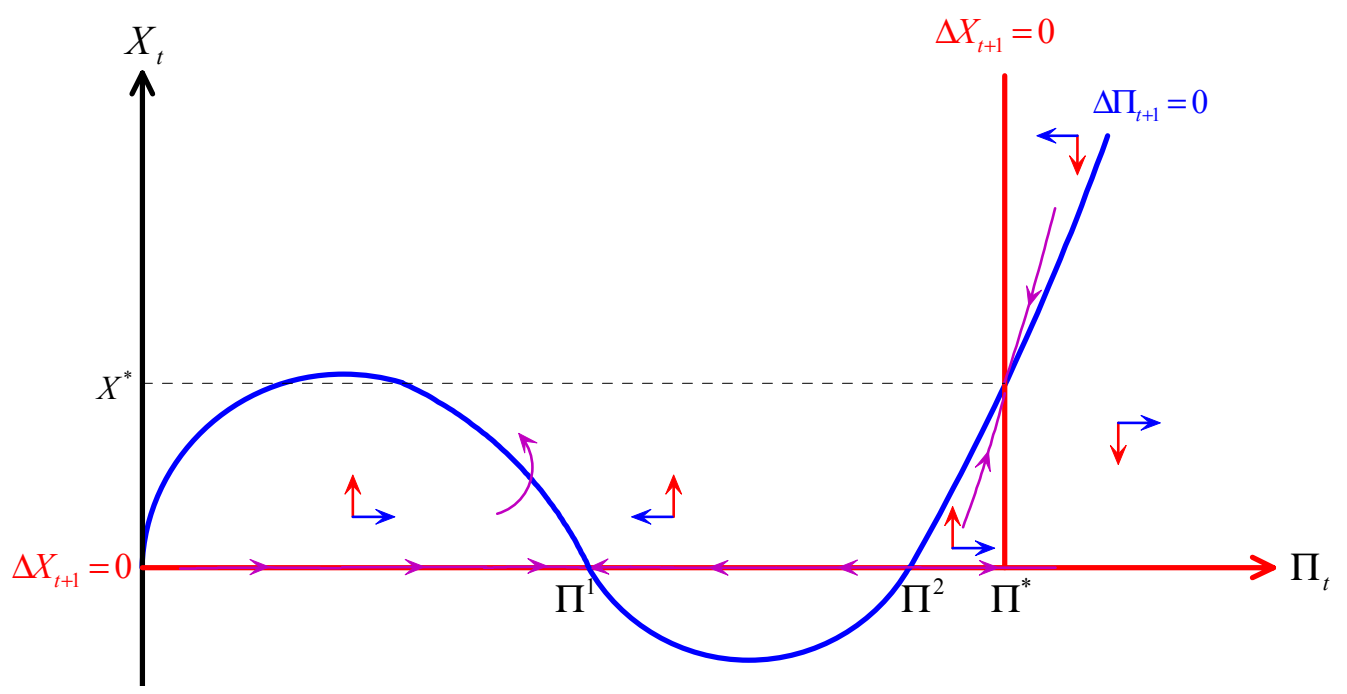

Figure 4

Now to be complete we have to say what happens when there are more than two potential equilibria of type $\mathcal{R}$. Under condition $(74)$ we will have an even number $K$ of such potential equilibria. It is easy to verify that potential equilibria with odd numbers have the same properties as $\Pi^{1}$ above, and potential equilibria with even numbers have the same properties as $\Pi^{2}$. So none of them can be reached, and the equilibrium of type $\mathcal{N} \mathcal{R}$ is globally determinate.

\section{$9 \quad$ Examples}

We want now to give a few examples where the Taylor principle does not hold, at least in the vicinity of the long run equilibrium, and nevertheless global determinacy obtains.

\subsection{A simple linear rule}

Let us take a linear interest rate rule:

$$
\Phi\left(\Pi_{t}\right)=A \Pi_{t}+B \quad A>0 \quad B>1
$$

From proposition 2, if $\Phi\left(\Pi_{t}\right) / \Pi_{t}>R^{0}=\gamma / \beta \quad \forall \Pi_{t}$, there will be global determinacy. A sufficient condition for this is that: 


$$
\beta A>\gamma
$$

Now let us evaluate the elasticity of this interest rate rule:

$$
\phi\left(\Pi_{t}\right)=\frac{A \Pi_{t}}{A \Pi_{t}+B}<1
$$

We see that global determinacy can be achieved eventhough the elasticity $\phi$ is always smaller than 1.

\subsection{Local interest rate pegging}

Let us take the following rule:

$$
\Phi\left(\Pi_{t}\right)=\left(1+i_{0}\right) \max \left[1,\left(\frac{\Pi_{t}}{\Pi_{0}}\right)^{\alpha}\right]
$$

The interest rate is pegged at $i_{0}$ for $\Pi_{t} \leq \Pi_{0}$ and then responds to inflation beyond $\Pi_{0}$. We would like to obtain the strong financial dominance condition (proposition 2), and thus we want the following expression:

$$
\left(1+i_{0}\right) \max \left[1,\left(\frac{\Pi_{t}}{\Pi_{0}}\right)^{\alpha}\right]-\Pi_{t} R^{0}
$$

to be positive for all values of $\Pi_{t}$. First, if we want this expression to become positive for large values of $\Pi_{t}$, we should have $\alpha \geq 1$. Secondly one shifts from one branch of $\Phi\left(\Pi_{t}\right)$ to the other at $\Pi_{t}=\Pi_{0}$. This intersection must be above the horizontal axis, so we must also have:

$$
\left(1+i_{0}\right)-\Pi_{0} R^{0} \geq 0
$$

Now the steady state equilibrium is at $\Pi^{*}=\Lambda / \gamma(1+n)$. We would like this long run equilibrium to occur in the zone where monetary policy is fully "inactive", i.e. where $\Pi_{t}<\Pi_{0}$. This will be achieved if:

$$
\Pi^{*}<\Pi_{0}
$$

Equations (80) and (81) define an interval for $\Pi_{0}$. It will be possible to find an adequate $\Pi_{0}$ if this interval is not void, which, combining (80) and (81), boils down to:

$$
\frac{1+i_{0}}{R^{0}}>\Pi^{*} \quad \text { or } \quad \frac{1+i_{0}}{\Pi^{*}}>R^{0}
$$

But this is essentially the "financial dominance" condition, expressed at the long run equilibrium. 


\section{Conclusions}

We studied global determinacy in non Ricardian monetary economies where new agents are born over time. The monetary policy was supposed to be conducted by using a "Taylor rule" which respects the zero lower bound on nominal interest rate.

We first saw that such economies have two types of equilibria, "Ricardian" and "non Ricardian".

Ricardian equilibria are similar to the equilibria in the traditional Ricardian model, and so are the conditions for global determinacy (appendix 2). Notably, the well known "Taylor principle" is a necessary (but not sufficient) condition for global determinacy.

Non Ricardian equilibria turn out, however, to have dramatically different properties, notably as far as local and global determinacy conditions are concerned. The "financial dominance" criterion, whether it applies to all inflation rates (proposition 2), or to a subset (proposition 3), is sufficient by itself to ensure existence and global determinacy. This criterion essentially says that the real rate of interest implied by the interest rate rule should be higher than the "autarkic" interest rate. 


\section{Appendix 1}

In this appendix we shall derive the fundamental equation (18). Consider the household's budget equation (4), and assume that $i_{t}$ is strictly positive. The household will thus satisfy the "cash in advance" equation exactly, so that $m_{j t}=P_{t} c_{j t}$ and the budget constraint is written:

$$
\omega_{j t+1}=\left(1+i_{t}\right) \omega_{j t}+P_{t} y_{t}-P_{t} \tau_{t}-\left(1+i_{t}\right) P_{t} c_{j t}
$$

Define the following nominal discount factors:

$$
Q_{t}=\frac{1}{\left(1+i_{0}\right) \ldots\left(1+i_{t-1}\right)} \quad Q_{0}=1
$$

and apply them to the budget constraint (83). This yields:

$$
Q_{t+1} \omega_{j t+1}=Q_{t} \omega_{j t}+Q_{t+1} P_{t}\left(y_{t}-\tau_{t}\right)-Q_{t} P_{t} c_{j t}
$$

If we now sum all the budget constraints (85) from time $t$ to infinity, and assume that $Q_{T} \omega_{j T}$ goes to zero as $T$ goes to infinity (this is the usual transversality condition), we obtain the household $j$ 's intertemporal budget constraint:

$$
\sum_{s=t}^{\infty} Q_{s} P_{s} c_{j s}=Q_{t} \omega_{j t}+\sum_{s=t}^{\infty} Q_{s+1} P_{s}\left(y_{s}-\tau_{s}\right)
$$

Maximizing the utility function (1) subject to the intertemporal budget constraint (86) yields household $j$ 's consumption function:

$$
Q_{t} P_{t} c_{j t}=(1-\beta)\left[Q_{t} \omega_{j t}+\sum_{s=t}^{\infty} Q_{s+1} P_{s}\left(y_{s}-\tau_{s}\right)\right]
$$

Summing this across the $N_{t}$ agents alive in period $t$, we obtain the aggregate consumption $C_{t}$ :

$$
Q_{t} P_{t} C_{t}=(1-\beta)\left[Q_{t} \Omega_{t}+N_{t} \sum_{s=t}^{\infty} Q_{s+1} P_{s}\left(y_{s}-\tau_{s}\right)\right]
$$

In equilibrium we have $C_{t}=Y_{t}$, so the equilibrium equation is:

$$
Q_{t} P_{t} Y_{t}=(1-\beta)\left[Q_{t} \Omega_{t}+N_{t} \sum_{s=t}^{\infty} Q_{s+1} P_{s}\left(y_{s}-\tau_{s}\right)\right]
$$

Divide both sides by $N_{t}$ and use $Y_{t}=N_{t} y_{t}$ :

$$
Q_{t} P_{t} y_{t}=(1-\beta)\left[\frac{Q_{t} \Omega_{t}}{N_{t}}+\sum_{s=t}^{\infty} Q_{s+1} P_{s}\left(y_{s}-\tau_{s}\right)\right]
$$


Rewrite equation (90) for $t+1$, and subtract it from (90). We obtain:

$$
Q_{t} P_{t} y_{t}-Q_{t+1} P_{t+1} y_{t+1}=(1-\beta)\left[\frac{Q_{t} \Omega_{t}}{N_{t}}-\frac{Q_{t+1} \Omega_{t+1}}{N_{t+1}}+Q_{t+1} P_{t}\left(y_{t}-\tau_{t}\right)\right]
$$

Now, noting that $M_{t}=P_{t} Y_{t}$ in equilibrium, divide the government's budget equation (9) by $N_{t}$ :

$$
\frac{Q_{t} \Omega_{t}}{N_{t}}=\frac{Q_{t+1} \Omega_{t+1}}{N_{t}}+Q_{t+1} P_{t} \tau_{t}+\left(Q_{t}-Q_{t+1}\right) P_{t} y_{t}
$$

and insert it into equation (91):

$$
Q_{t+1} P_{t+1} y_{t+1}=\beta Q_{t} P_{t} y_{t}-(1-\beta)\left(\frac{1}{N_{t}}-\frac{1}{N_{t+1}}\right) Q_{t+1} \Omega_{t+1}
$$

Now multiply equation (93) by $N_{t+1} / Q_{t+1}$. We obtain the equation which describes the dynamics of nominal income:

$$
P_{t+1} Y_{t+1}=\beta \frac{N_{t+1}}{N_{t}}\left(1+i_{t}\right) P_{t} Y_{t}-(1-\beta)\left(\frac{N_{t+1}}{N_{t}}-1\right) \Omega_{t+1}
$$

Assuming finally $N_{t+1} / N_{t}=1+n$, we obtain:

$$
P_{t+1} Y_{t+1}=\beta(1+n)\left(1+i_{t}\right) P_{t} Y_{t}-(1-\beta) n \Omega_{t+1}
$$

which is equation (18).

\section{Appendix 2}

Although the main object of our study is the "new" non Ricardian equilibria, we shall give here some sufficient global determinacy conditions for "Ricardian equilibria", i.e. equilibria of type $\mathcal{R}$. We shall see that these conditions are similar to those found in traditional Ricardian models (proposition 1).

Proposition 4 Consider potential equilibria of type $\mathcal{R}$, characterized by inflation rates $\Pi^{k}, 1 \leq k \leq K$ such that $\Phi\left(\Pi^{k}\right) / \Pi^{k}=R^{0}$. Then the only possible globally determinate equilibrium is that with the highest inflation rate $\Pi^{K}$. This equilibrium will be globally determinate if:

$$
\begin{gathered}
\phi\left(\Pi^{K}\right)>1 \\
\Pi^{K-1}<\Pi^{*}<\Pi^{K}
\end{gathered}
$$


Proof. Under condition (96) there is an even number of potential equilibria, and the only possible globally determinate one corresponds to the highest inflation rate, i.e. $k=K$. Let us start with the case where there are two such equilibria of type $\mathcal{R}$ ( $\Pi^{1}$ and $\Pi^{2}$ ) and, from (97), $\Pi^{1}<\Pi^{*}<\Pi^{2}$. This is represented in figure 5 .

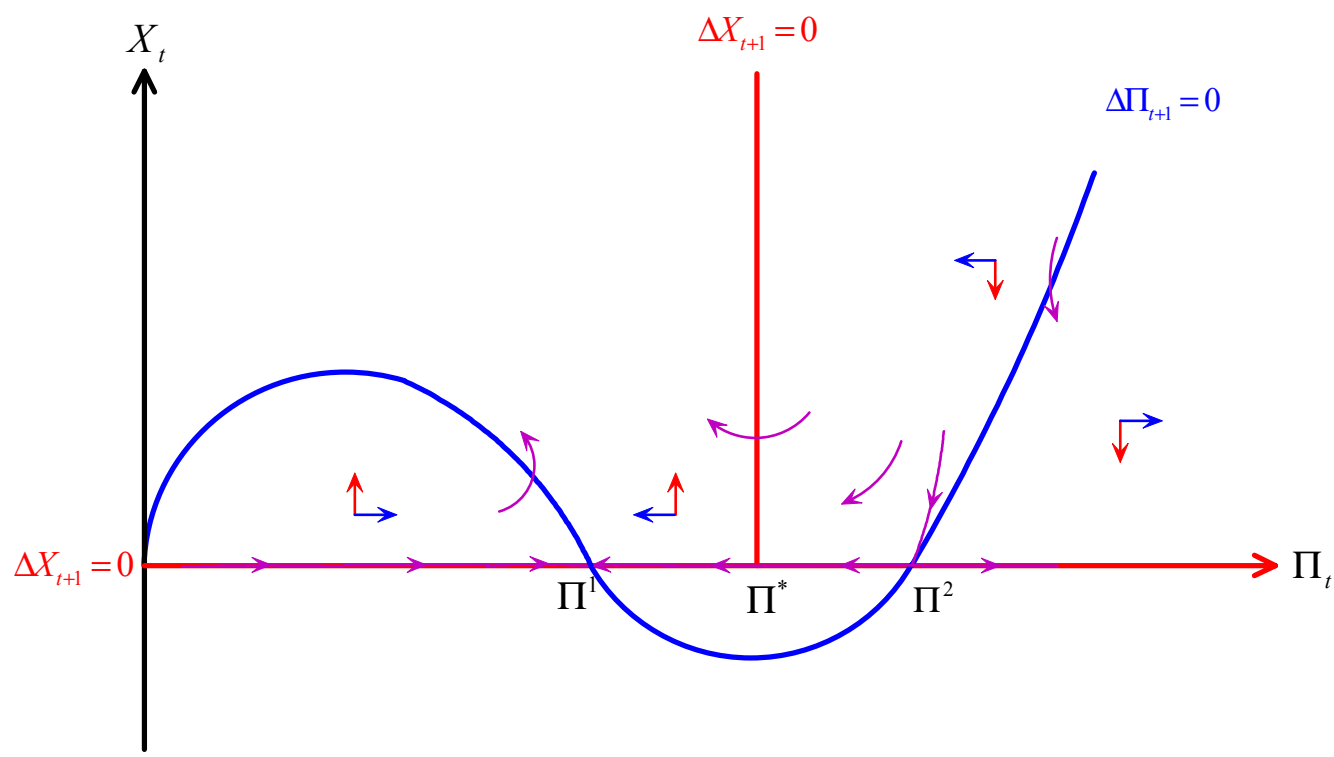

Figure 5

The $\Pi^{2}$ equilibrium displays saddle path dynamics. We must of course check that the transversality condition (50):

$$
\frac{\Lambda}{(1+n) R_{0}}<\Pi^{2}
$$

holds in this equilibrium. But condition (96) implies:

$$
\Pi^{*}=\frac{\Lambda}{(1+n) \gamma}<\Pi^{2}
$$

which implies (50) since $R_{0}=\gamma / \beta$.

Now let us consider the potential equilibrium $\Pi^{1}$. From lemma $1, \phi\left(\Pi^{1}\right)<$ 1. Further from the results of section 7.2 we see that it displays saddle path dynamics, but on the other hand the converging branch is included in the horizontal axis, so that if $X_{0}>0$ it cannot be reached.

Finally let us examine the more general case with an even number $K$ of potential equilibria of type $\mathcal{R}$. Odd numbered equilibria have the same properties as equilibrium $\Pi^{1}$ above, and cannot be reached. Even numbered equilibria are characterized by two roots $\phi\left(\Pi^{k}\right)>1$ and $\Pi^{*} / \Pi^{k}>1$. Since both roots are of modulus greater than 1 , these equilibria cannot be reached either. 


\section{References}

[1] Alstadheim, R., Henderson, D., 2004. Price-level determinacy, lower bounds on the nominal interest rate, and liquidity traps, Board of Governors of the Federal Reserve System (U.S.), International Finance Discussion Papers, 795.

[2] Barro, R. J., 1974. Are government bonds net wealth?, Journal of Political Economy, 82, 1095-1117.

[3] Bénassy, J.P., 2000. Price level determinacy under a pure interest rate peg, Review of Economic Dynamics, 3, 194-211.

[4] Bénassy, J.P., 2005. Interest rate rules, price determinacy and the value of money in a non Ricardian world, Review of Economic Dynamics, 8, 651-667.

[5] Benhabib, J., Schmitt-Grohé, S., Uribe, M., 2001a. The perils of Taylor rules, Journal of Economic Theory, 96, 40-69.

[6] Benhabib, J., Schmitt-Grohé, S., Uribe, M. 2001b. Monetary policy and multiple equilibria, American Economic Review, 91, 167-186.

[7] Benhabib, J., Schmitt-Grohé, S., Uribe, M., 2002. Avoiding liquidity traps, Journal of Political Economy, 110, 535-563.

[8] Blanchard, O. J., Kahn, C. M., 1980. The solution of linear difference models under rational expectations, Econometrica, 48, 1305-1311.

[9] Samuelson, P. A., 1958. An exact consumption-loan model of interest with or without the social contrivance of money, Journal of Political Economy, 66, 467-482.

[10] Sargent, T. J., Wallace, N., 1975. Rational expectations, the optimal monetary instrument and the optimal money supply rule, Journal of Political Economy, 83, 241-254.

[11] Taylor, J. B., 1993. Discretion versus policy rules in practice, CarnegieRochester Series on Public Policy, 39, 195-214.

[12] Taylor, J. B., 1998. Monetary policy and the long boom, Federal Reserve Bank of Saint-Louis Review, 80, n 6, 3-11.

[13] Wallace, N., 1980. The overlapping generations model of fiat money in Kareken, J., Wallace, N. eds, Models of Monetary Economies (Federal Reserve Bank of Minneapolis, Minneapolis) 49-82.

[14] Weil, P., 1987. Permanent budget deficits and inflation, Journal of Monetary Economics, 20, 393-410. 
[15] Weil, P., 1991. Is money net wealth?, International Economic Review, 32, 37-53.

[16] Woodford, M., 1999. Price level determination under interest rate rules, working paper, Princeton University.

[17] Woodford, M., 2003. Interest and Prices: Foundations of a Theory of Monetary Policy, Princeton University Press, Princeton and Oxford. 